\title{
Article \\ Activated STAT3 Is a Novel Regulator of the XRCC1 Promoter and Selectively Increases XRCC1 Protein Levels in Triple Negative Breast Cancer
}

\author{
Griffin Wright ${ }^{1,2}$, Manoj Sonavane ${ }^{1,2}$ and Natalie R. Gassman 1,2,*(D) \\ 1 Department of Physiology and Cell Biology, University of South Alabama College of Medicine, \\ 307 N University Blvd, Mobile, AL 36688, USA; gmw1821@jagmail.southalabama.edu (G.W.); \\ msonavane@southalabama.edu (M.S.) \\ 2 Mitchell Cancer Institute, University of South Alabama, 1660 Springhill Avenue, Mobile, AL 36604-1405, USA \\ * Correspondence: nrgassman@southalabama.edu
}

check for updates

Citation: Wright, G.; Sonavane, M.; Gassman, N.R. Activated STAT3 Is a Novel Regulator of the XRCC1

Promoter and Selectively Increases XRCC1 Protein Levels in Triple Negative Breast Cancer. Int. J. Mol. Sci. 2021, 22, 5475. https://doi.org/ $10.3390 /$ ijms 22115475

Academic Editor:

Kazuhiko Kuwahara

Received: 31 March 2021

Accepted: 20 May 2021

Published: 22 May 2021

Publisher's Note: MDPI stays neutral with regard to jurisdictional claims in published maps and institutional affiliations.

Copyright: (c) 2021 by the authors. Licensee MDPI, Basel, Switzerland. This article is an open access article distributed under the terms and conditions of the Creative Commons Attribution (CC BY) license (https:// creativecommons.org/licenses/by/ $4.0 /)$.

\begin{abstract}
Base Excision Repair (BER) addresses base lesions and abasic sites induced by exogenous and endogenous stressors. X-ray cross complementing group 1 (XRCC1) functions as a scaffold protein in BER and single-strand break repair (SSBR), facilitating and coordinating repair through its interaction with a host of critical repair proteins. Alterations of XRCC1 protein and gene expression levels are observed in many cancers, including colorectal, ovarian, and breast cancer. While increases in the expression level of XRCC1 are reported, the transcription factors responsible for this up-regulation are not known. In this study, we identify the signal transducer and activator of transcription 3 (STAT3) as a novel regulator of XRCC1 through chromatin immunoprecipitation. Activation of STAT3 through phosphorylation at Y705 by cytokine (IL-6) signaling increases the expression of XRCC1 and the occupancy of STAT3 within the XRCC1 promoter. In triple negative breast cancer, the constitutive activation of STAT3 upregulates XRCC1 gene and protein expression levels. Increased expression of XRCC1 is associated with aggressiveness and resistance to DNA damaging chemotherapeutics. Thus, we propose that activated STAT3 regulates XRCC1 under stress and growth conditions, but constitutive activation in cancers results in dysregulation of XRCC1 and subsequently BER and SSBR.
\end{abstract}

Keywords: base excision repair; STAT transcription factor; STAT3; breast cancer; DNA repair; chemoresistance; cytokine; stress; XRCC1

\section{Introduction}

Base excision repair (BER) is an essential DNA repair pathway responsible for detecting and repairing abasic sites and base lesions. X-ray cross complementing group 1 (XRCC1) is a scaffold protein in the BER pathway. Although it lacks enzymatic activity, XRCC1 has a critical role in BER through recruiting and coordinating other DNA repair proteins, like DNA polymerase $\beta$ (POL $\beta$ ) and DNA ligase III (LIG3), at DNA damage sites. XRCC1's facilitation of protein-protein interactions provides for overlap in functions between the BER and single-strand break repair (SSBR) pathways [1,2]. In addition to BER and SSBR, XRCC1 also participates in double-strand break repair (DSBR) through its interaction with PARP1 in the error-prone alternative non-homologous end-joining (a-NHEJ) [3-5], as well as in nucleotide excision repair (NER) through interaction with LIG3 [6].

Given XRCC1's critical scaffold functions, it is unsurprising that XRCC1 is ubiquitously expressed in most tissues, though low levels of XRCC1 are found in terminally differentiated muscle cells and neurons, causing impaired BER [7,8]. In tissues that should have abundant amounts of XRCC1, its loss can have profound consequences. In mice, Xrcc1-deficiency is lethal at day 7 [9]. Human cells that have lower levels of XRCC1 show significant sensitivity to DNA damaging agents like methyl methanesulfonate (MMS), 
poly(ADP-ribose) polymerase (PARP) inhibitors, and other DNA damage response and repair inhibitors [10-14]. Additionally, mutations in XRCC1 that reduce its ability to bind PARP1, POL $\beta$, or interact with DNA have been shown to increase hypersensitivity to DNA damaging agents and increase genomic instability and chromosomal aberrations, promoting transformation [15-22]. While several single nucleotide polymorphisms, R399Q and $\mathrm{R} 280 \mathrm{H}$, have been correlated with cancer risk, variations in the gene and protein expression levels of XRCC1 are more commonly noted, particularly in ovarian, breast, and gastric cancers [14,23-28].

In breast cancer, low expression of XRCC1 correlated with improved response to poly(ADP-ribose) polymerase (PARP) inhibitors [14,26,27]. However, the prevalence of XRCC1 deficiency was $~ 15 \%$, although XRCC1 deficiency was closer to $30 \%$ when breast tumors were BRCA1 deficient $[13,14]$. When we examined XRCC1 expression more closely in breast cancer using the UALCAN TCGA portal, we noted significantly increased expression of XRCC1 in luminal (566 cases, $p<10^{-12}$ compared with normal) and triple negative breast cancers (TNBC, 116 cases, $p<0.001$ ) [11,29]. TNBC model cell lines confirmed the overexpression of XRCC1 at the gene and protein level [11,30,31]. XRCC1 overexpression is correlated with increased aggressive features and reduced cancer-specific survival in ovarian tumor samples [23]. Overexpression of XRCC1 also promotes chemoresistance in ovarian, gastric, and gallbladder cancer cell lines [23-25].

Despite reports demonstrating the overexpression of XRCC1, the transcriptional regulation of XRCC1 remains poorly understood, with only two transcription regulators identified thus far. The cell cycle regulator E2F transcription factor 1 (E2F1) was the first transcription factor regulating XRCC1 to be identified [32]. E2F1 was shown to induce a robust BER response through increased XRCC1 gene and protein expression following DNA damage induced by the alkylating agent MMS [32]. More recently, the basal transcription factor, Sp1, was confirmed to control the transcription of XRCC1 [33]. This transcriptional regulation was shown to be governed by the DNA damage sensor ataxia telangiectasia mutated kinase (ATM). Following persistent DNA damage, ATM becomes phosphorylated and, in turn, phosphorylates Sp1. Phosphorylation of Sp1-reduced XRCC1 expression, promoting apoptosis [33].

Expression of BER factors, like 3-alkyladenine DNA glycosylase (AAG) or N-methylpurine DNA glycosylase (MPG), 8-oxoguanine DNA glycosylase 1 (OGG1), apurinic/apyrimidinic endonuclease 1 (APE1), poly(ADP-ribose) polymerase 1 (PARP1), POL $\beta$, and now XRCC1, have been shown to influence tumor characteristics and dictate chemotherapy response [14,23-25,28,34-37]. While several transcription regulators have been identified for PARP1, POL $\beta$, and several DNA glycosylases, our understanding of the transcriptional regulation of these genes is still developing $[38,39]$. More importantly, the transcriptional regulation of XRCC1 is poorly understood in general, and even less is known about the drivers of dysregulation in cancer.

In this study, we have identified the signal transducer and activator of transcription 3 (STAT3) as a novel transcriptional regulator of XRCC1. The STAT family of transcription factors play a unique role in signal transduction and are critical to mediating cellular responses to external stimuli, particularly from cytokines and mitogens. During development and growth, STAT family signaling is critical to tissue differentiation and function [40]. However, aberrant STAT3 signaling has been linked to many of the hallmarks of cancer, including cell growth, proliferation, survival, immune evasion, metastasis, and angiogenesis [41]. Here, we found that STAT3 binding at the XRCC1 promoter is significantly higher in TNBC models but is also observed in nontumorigenic human embryonic kidney cells (HEK293T). Occupancy at the binding site is increased when STAT3 is over-expressed or activated by cytokine IL-6 signaling. Importantly, in TNBC, the constitutive activation of STAT3 drives the increased expression of XRCC1, and inhibition of STAT3 or decreased expression of STAT3 reduces the expression of XRCC1. These data indicate that STAT3 conditionally regulates XRCC1 expression and contributes to the overexpression of XRCC1 observed in TNBC. 


\section{Results}

2.1. XRCC1 Promoter Has Active Regions Driving Reporter Expression Not Associated with Known Transcription Factors

We performed a promoter-luciferase assay to identify the active regions of the XRCC1 promoter that are capable of driving reporter expression. A series of truncated promoter regions were inserted into a pGL3-Basic vector backbone plasmid, and the luminescence values were measured in MDA-231 and HEK293T cells (Figure 1 and Supplementary Materials Figure S1). Using this assay, we identified a region capable of driving reporter expression between -612 and -35 that was not previously associated with known transcription factors $[32,33]$.

A
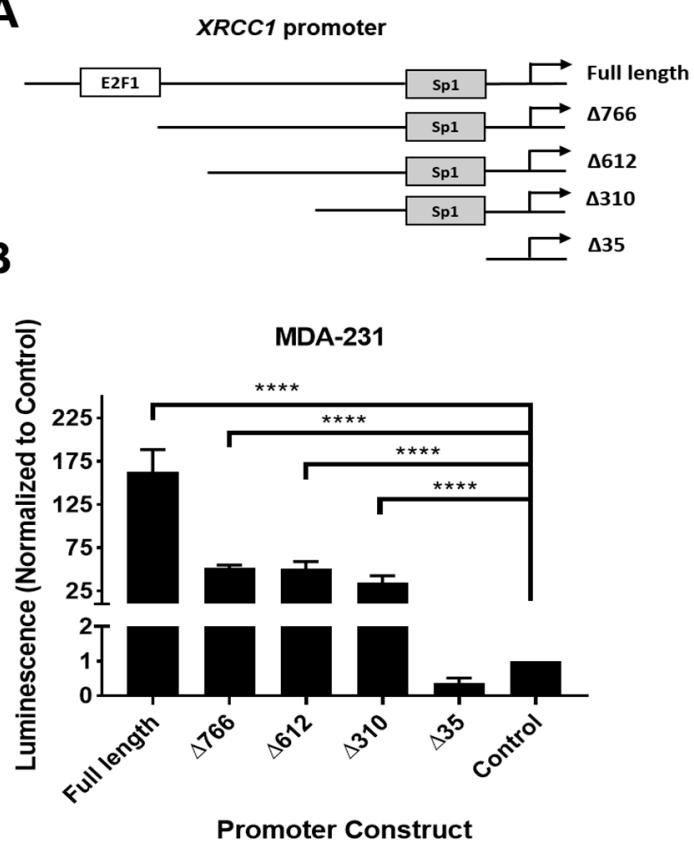

Figure 1. XRCC1 promoter expression in MDA-231 cells has actively transcribed regions between -612 and -35 . (A) XRCC1 promoter fragments with known transcription factor sites were inserted into the pGL3 luciferase reporter. (B) Reporter plasmids were transfected into MDA-231, and luminescence was read after $24 \mathrm{~h} .{ }^{* * * *} p<0.0001$.

To identify potential transcription factor candidates associated with this region, we performed a promoter binding ELISA (Material and Methods). Multiple potential binders within the -612 and -35 XRCC1 promoter region were identified, including CBF, NF1, HNF4, and STAT3 (Supplementary Materials Figure S2). Of the transcription factors showing positive binding, we found STAT3 to be of particular interest due to its prominent role in multiple cancers, including triple negative breast cancer [42,43]. Additionally, we performed an in silico search using CiiiDER (www.ciiider.org, accessed on 9 November 2020) to confirm potential transcription factors. CiiiDER predicted potential transcription factor binding sites in regions of interest and confirmed a potential STAT3 binding site within the -612 to -35 region of the XRCC1 promoter (Figure 2A) [44]. 
A

-452 AGTGGGAGGATCCCTTGGCCCCAGGAGACAGGGGTTGCAGAAAGCCG AGATCGTGCCACTGCACTCCATCCTGGGTGAGAGAGCAAGACCCTGTCT -358

B

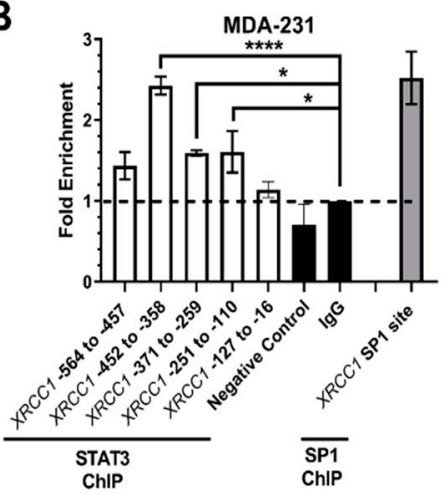

C

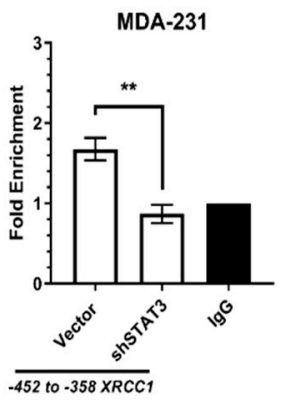

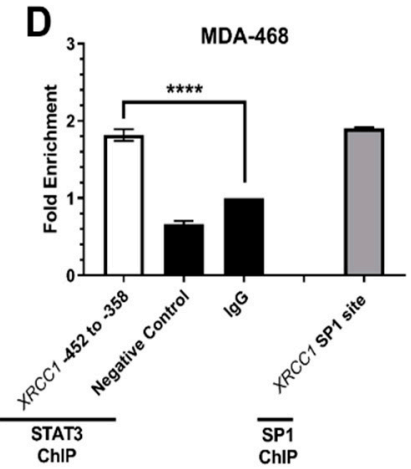

Figure 2. The XRCC1 promoter contains a STAT3 binding site. (A) CiiiDER identified an STAT3 binding sequence within the XRCC1 promoter (red font). (B) ChIP analysis of XRCC1 promoter in MDA-231 cells show a significant enrichment of STAT3 between -452 and -358. (C) The knockdown of STAT3 with shRNA \#1 eliminates STAT3 binding within the -452 to -358 fragment. CHiP using primers specific for the SP1 binding site within the XRCC1 promoter was performed as a positive control. (D) STAT3 binding also occurs within the -452 to -358 fragment of the XRCC1 promoter in MDA-468 cells. ${ }^{*} p<0.05^{* *} p<0.01,{ }^{* * * *} p<0.0001$.

\subsection{ChIP Confirmed the STAT3 Binding Site within the XRCC1 Promoter}

Chromatin Immunoprecipitation (ChIP) was utilized to map the regions of the XRCC1 promoter in MDA-231 that contain the STAT3 binding site. A significant fold enrichment above IgG isotype control $(2.426 \pm 0.11, p<0.001)$ indicated that binding of STAT3 occurred within a 96-base pair $(\mathrm{bp})$ region between -452 to -358 of the XRCC1 promoter (Figure $2 \mathrm{~B}$ ). Knockdown of STAT3 with shRNA \#1 (sh\#1) in MDA-231 eliminated STAT3 binding in the -452 to -358 region (Figure 2C). STAT3 binding was further confirmed in another TNBC cell line, MDA-468, where $1.826 \pm 0.066(p<0.0001)$ enrichment in binding at the -452 to -358 region of the XRCC1 promoter was seen above IgG isotype control and consistent with the known SP1 binding site (Figure 2D). These findings indicate that the XRCC1 promoter contains a STAT3 binding site with significant occupancy in TNBC cell lines.

\subsection{STAT3 Expression Attenuated XRCC1 Expression}

The transcription factor activity of STAT3 is activated by its phosphorylation at Y705 (pSTAT3) and subsequent dimerization and translocation into the nucleus. To confirm the regulatory role of STAT3 in XRCC1 expression, we first used two shRNA constructs to target STAT3 mRNA and reduce its gene expression in MDA-231. Each shRNA construct reduced the protein expression of STAT3 and reduced the presence of activated phosphorylated STAT3 (pSTAT3, Figure 3A). The reduction in STAT3 significantly reduced XRCC1 protein expression (sh\#1 $0.435 \pm 0.019$ and sh\#2 $0.313 \pm 0.063$ ) levels at $48 \mathrm{~h}$ (Figure 3B) and reduced XRCC1 mRNA levels (sh\#1: $0.506 \pm 0.089$ and sh\#2: $0.693 \pm 0.015$ ) (Figure 3C). We then increased the expression of STAT3 by ectopic expression of a FLAG-tagged protein (Figure 4). Overexpression of STAT3 also increased the levels of activated STAT3 (pSTAT3). Increased levels of STAT3 and pSTAT3 resulted in increased XRCC1 protein $(2.07 \pm 0.19$, Figure 4B) and mRNA (3.52 \pm 0.086 ) levels (Figure 4C). 
A
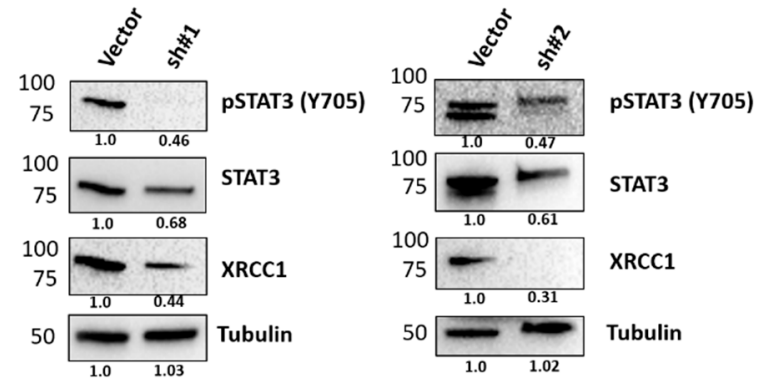

B

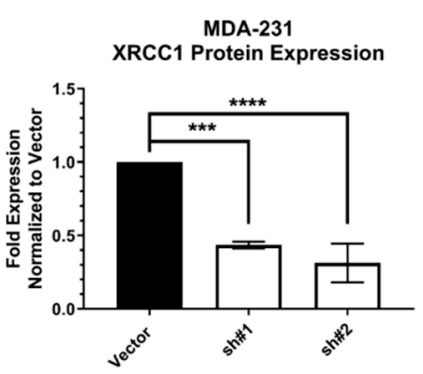

C

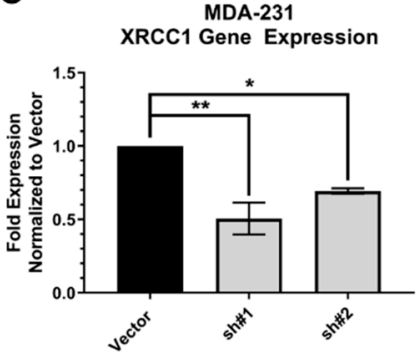

Figure 3. shRNA knockdown of STAT3 reduces the expression of XRCC1 in MDA-231 cells. (A) Representative immunoblots of phospho-STAT3 (Y705), STAT3 and XRCC1 protein expression following shRNA mediated knockdown of STAT3. $\alpha$-tubulin is used as a loading control. (B) Quantification of protein expression changes in XRCC1 resulting from shRNA-mediated knockdown of STAT3. (C) Quantification of XRCC1 mRNA expression following shRNA-mediated knockdown of STAT3. ${ }^{*} p<0.05,{ }^{* *} p<0.01,{ }^{* * *} p<0.001,{ }^{* * * *} p<0.0001$.

A

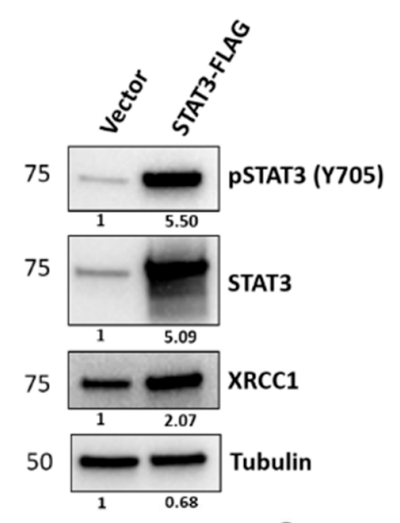

B

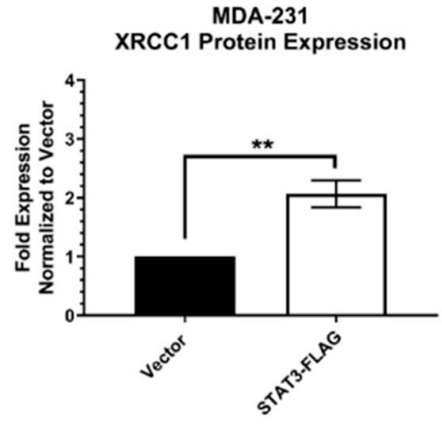

C

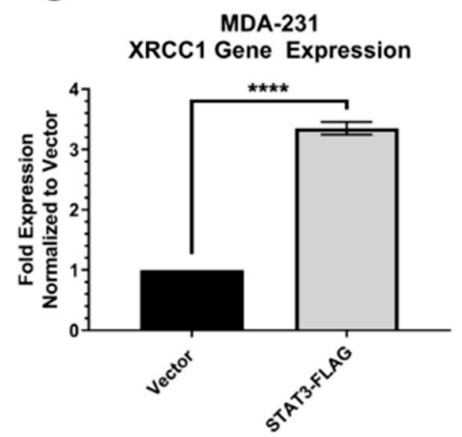

Figure 4. Ectopic overexpression of STAT3 increases the expression of XRCC1 in MDA-231 cells. (A) Representative immunoblot of phospho-STAT3 (Y705), STAT3 and XRCC1 protein expression following ectopic expression of STAT3-FLAG. $\alpha$-tubulin is used as a loading control. (B) Quantification of protein expression changes in XRCC1 resulting from ectopic expression of STAT3-FLAG. (C) Quantification of XRCC1 mRNA expression following ectopic expression of STAT3-FLAG. ${ }^{* *} p<0.01$, $* * * * p<0.0001$. 
Given that PSTAT3 is the active transcription factor, we also specifically targeted the activated STAT3 using the pSTAT3 inhibitor, alantolactone, to block phosphorylation of STAT3 without significantly reducing the protein levels of STAT3. Pharmacological inhibition of pSTAT3 with $15 \mu \mathrm{M}$ alantolactone produced the same trend as the shRNA constructs (Figure 5). In MDA-231, levels of pSTAT3 were reduced at $4 \mathrm{~h}$ of alantolactone exposure, but the protein levels of STAT3 were only slightly reduced (Figure 5A). However, XRCC1 protein $(0.649 \pm 0.051$, Figure $5 \mathrm{~B})$ and XRCC1 mRNA expression levels $(0.675 \pm 0.038$, Figure $5 \mathrm{C}$ ) were significantly reduced in the presence of alantolactone. A similar trend was observed in MDA-468 cells, which showed a high STAT3 protein expression level (Figure 5D). Treatment with alantolactone significantly reduced the presence of pSTAT3 (Figure 5D) and both XRCC1 protein (0.760 \pm 0.026 , Figure 5E) and mRNA expression levels $(0.758 \pm 0.020$, Figure $5 F)$. A significant reduction of XRCC1 protein and mRNA levels, along with STAT3 and pSTAT3 expression, was maintained even after $24 \mathrm{~h}$ of exposure to $15 \mu \mathrm{M}$ alantolactone in the MDA-231 cells (Supplementary Materials Figure S3).

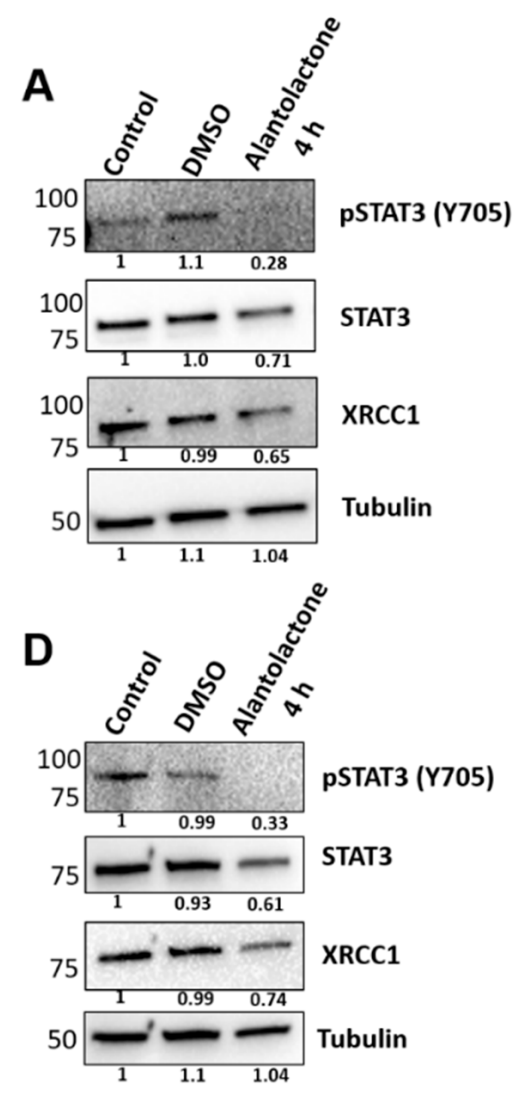

B

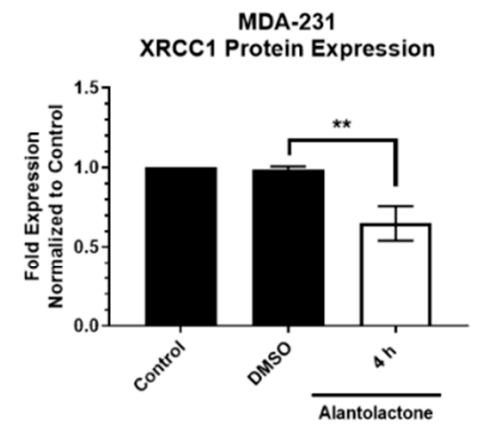

E

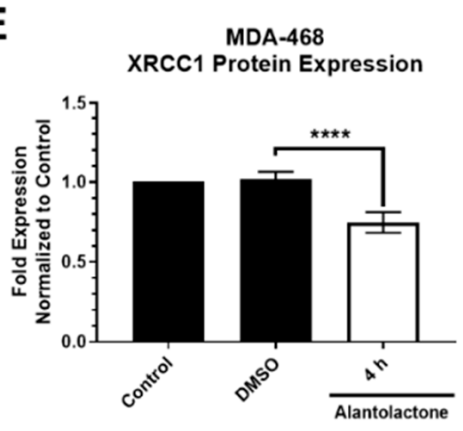

C

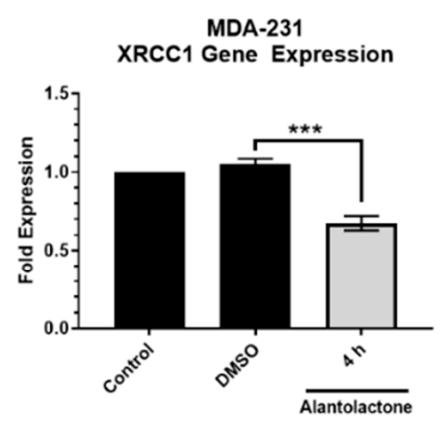

$\mathbf{F}$

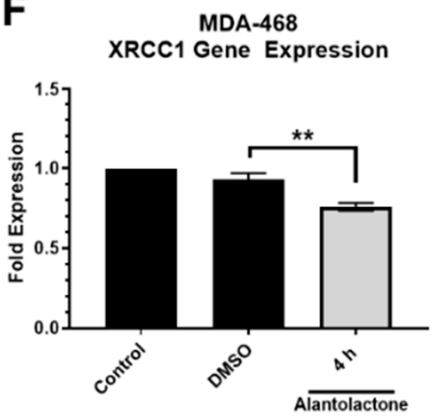

Figure 5. Chemical inhibition of the phosphorylation of STAT3 at Y705 by alantolactone decreases the expression of XRCC1 in MDA-231 and MDA-468 cells. (A) Representative immunoblots of phospho-STAT3 (Y705), STAT3 and XRCC1 protein expression after $4 \mathrm{~h}$ of exposure to $15 \mu \mathrm{M}$ alantolactone in MDA-231 cells. $\alpha$-tubulin is used as a loading control. (B) Quantification of protein expression changes in XRCC1 resulting from $4 \mathrm{~h}$ of alantolactone exposure in MDA-231 cells. (C) Quantification of XRCC1 mRNA expression following $4 \mathrm{~h}$ of alantolactone exposure in MDA-231 cells. (D) Representative immunoblots of phospho-STAT3 (Y705), STAT3 and XRCC1 protein expression after $4 \mathrm{~h}$ of exposure to $15 \mu \mathrm{M}$ alantolactone in MDA-468 cells. (E) Quantification of protein expression changes in XRCC1 resulting from $4 \mathrm{~h}$ of alantolactone exposure in MDA-468 cells. (F) Quantification of XRCC1 mRNA expression following $4 \mathrm{~h}$ of alantolactone exposure in MDA-468 cells. ${ }^{* *} p<0.01,{ }^{* * *} p<0.001,{ }^{* * * *} p<0.0001$. 


\subsection{STAT3 Regulation Is Prevalent in TNBC}

STAT3 is constitutively activated in TNBC, but levels of pSTAT3 are more tightly regulated in normal tissues and expressed at a much lower level $[43,45,46]$. Therefore, to determine if STAT3 regulation of XRCC1 is specific to TNBC, we measured STAT3 binding and activation in the human embryonic kidney cell line HEK293T. The ChIP of HEK293T cells showed a very low binding occupancy of STAT3 in the -452 to -358 region $(1.50 \pm 0.13)$ (Figure 6A). Immunoblotting also showed low levels of STAT3 and pSTAT3 in these cells (Figure 6B and Supplementary Materials Figure S4). Ectopic expression of the FLAG-tagged STAT3 increased STAT3 and pSTAT3 and subsequently increased the binding occupancy of STAT3 in the -452 to -358 region ( $3.93 \pm 0.82$, Figure $6 \mathrm{~A})$. Interestingly, the ectopic expression of STAT3 in HEK293T did not significantly increase XRCC1 protein content $(1.03 \pm 0.035)$, indicating that STAT3 has a less significant role in regulating XRCC1 expression in HEK293T and occurs through a cancer-related, possibly TNBC-specific, mechanism.

A

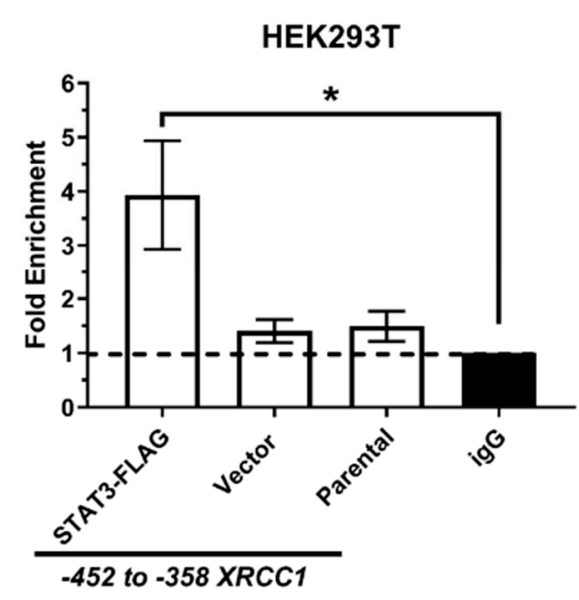

B

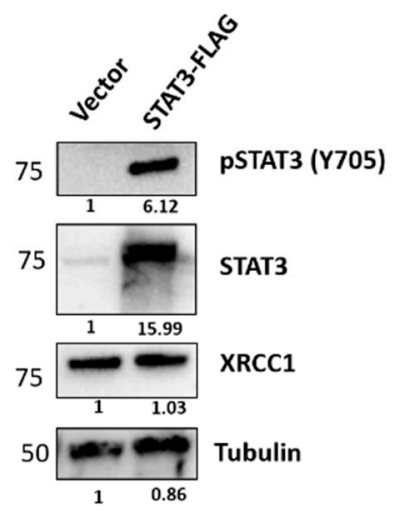

Figure 6. Ectopic overexpression of STAT3 increases STAT3 occupancy within the XRCC1 promoter in HEK293T cells. (A) ChIP analysis of STAT3 binding to the -452 to -358 XRCC1 promoter fragment. * $p<0.05$ (B) Representative immunoblots of phospho-STAT3 (Y705), STAT3 and XRCC1 protein expression following ectopic expression of STAT3-FLAG. $\alpha$-tubulin is used as a loading control.

To understand the specificity for TNBC, we examined physiologically relevant mechanisms for STAT3 regulation of XRCC1 in TNBC. IL-6 is a negative prognostic marker in breast cancer patients mainly due to its role in regulating STAT3 and its downstream targets promoting tumor cell proliferation, survival, and angiogenesis [43,47]. IL-6 is known to increase phosphorylation of STAT3 through JAK activation. Therefore, we examined if IL-6 activated STAT3 and resulted in changes in XRCC1 expression. Following exposure to IL-6 $(50 \mathrm{ng} / \mathrm{mL}$ ) for $30 \mathrm{~min}, 1$, and $4 \mathrm{~h}$, a significant increase in pSTAT3 was observed in MDA-231 cells and correlated with an increase in expression of XRCC1 at both the gene and protein levels (Figure 7). 
A

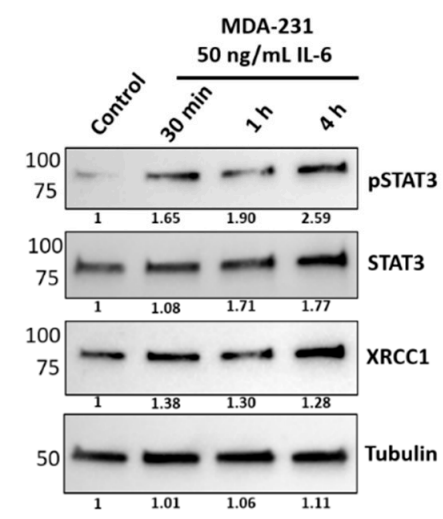

B

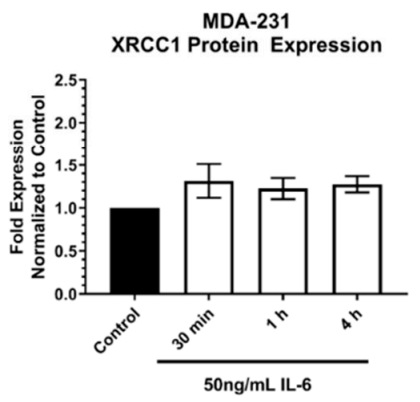

C

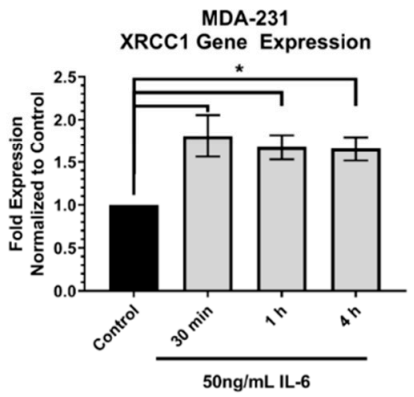

Figure 7. IL-6 increases phospho-STAT3 and increases the expression of XRCC1 in MDA-231. (A) Representative immunoblot of phospho-STAT3 (Y705), STAT3 and XRCC1 protein expression after $30 \mathrm{~min}, 1$ and $4 \mathrm{~h}$ of exposure to $50 \mathrm{ng} / \mathrm{mL}$ IL-6. $\alpha$-tubulin is used as a loading control. (B) Quantification of protein expression changes in XRCC1 resulting from $50 \mathrm{ng} / \mathrm{mL}$ IL-6 exposure. (C) Quantification of XRCC1 mRNA expression following $50 \mathrm{ng} / \mathrm{mL}$ IL-6 exposure. ${ }^{*} p<0.05$.

We further confirmed the induced activation of PSTAT3 and regulation of XRCC1 expression in HEK293T cells (Figure 8). HEK293T cells exposed to IL-6 showed increased activation of STAT3 (Figure 8A) and significantly increased STAT3 occupancy at the XRCC1 promoter $(2.20 \pm 0.26$, Figure $8 \mathrm{~B})$. XRCC1 gene and protein expression also increased in HEK293T cells exposed to IL-6 (Figure 8C,D), supporting the conditional regulation of XRCC 1 by STAT3 after physiological stress.
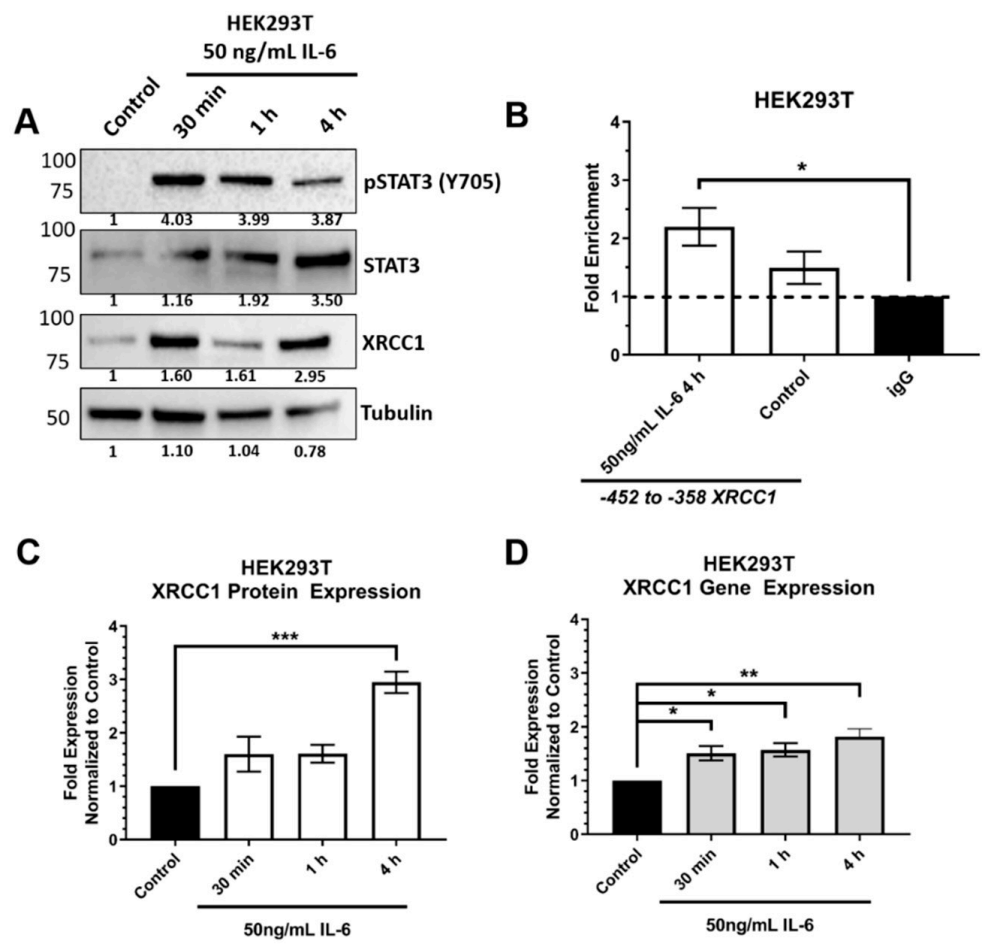

Figure 8. IL-6 increases phospho-STAT3, increases the occupancy of STAT3 at the XRCC1 promoter, and increases the expression of XRCC1 in HEK293T. (A) Representative immunoblot of phosphoSTAT3 (Y705), STAT3 and XRCC1 protein expression after $30 \mathrm{~min}, 1$ and $4 \mathrm{~h}$ of exposure to $50 \mathrm{ng} / \mathrm{mL}$ IL-6. $\alpha$-tubulin is used as a loading control. (B) ChIP analysis shows that IL-6 increases the STAT3 occupancy on the XRCC1 promoter. (C) Quantification of protein expression changes in XRCC1 resulting from $50 \mathrm{ng} / \mathrm{mL}$ IL-6. (D) Quantification of XRCC1 mRNA expression following $50 \mathrm{ng} / \mathrm{mL}$ IL-6. ${ }^{*} p<0.05,{ }^{* *} p<0.01,{ }^{* * *} p<0.001$. 
We also confirmed that pSTAT3 activation by the mitogen, epidermal growth factor (EGF), would also increase the gene and protein expression of XRCC1 in MDA-231 cells (Supplementary Materials Figure S5). Exposure to $30 \mathrm{ng} / \mathrm{mL}$ EGF activated STAT3, as well as the epidermal growth factor receptor (EGFR), and increased the protein and gene expression of XRCC1 within $24 \mathrm{~h}$ of exposure (Supplementary Materials Figure S5).

\section{Discussion}

Dysregulation of DNA repair proteins is a hallmark of cancer. Changes in the expression of DNA repair proteins can increase susceptibility to DNA damaging therapies or increase chemoresistance $[11,27,30]$. While various factors can regulate gene expression, transcription factors play a critical role in basal transcription and response to stress and stimuli. Despite the critical role BER has in addressing exogenous and endogenous threats, our knowledge of the transcription factors that regulate BER factors is lacking [38,39]. Surprisingly, only two transcription factors, E2F1 and Sp1, have been identified in the transcriptional regulation of XRCC1 [32,33].

In this study, we have identified a novel regulator of XRCC1, STAT3, which selectively upregulates XRCC1 in TNBC. Previously, we showed that alterations in XRCC1 gene and protein expression occur across a panel of TNBC cell lines [11]. Here, we determined that STAT3 binds within the XRCC1 promoter in MDA-231, MDA-468, and HEK293T cells (Figures 2, 6 and 8). Yet, the site only has significant occupancy when STAT3 is activated. Constitutive activation of STAT3 occurs in TNBC cells and is reflected by increased occupancy at the binding site (Figure 2). However, pSTAT3 is low in the HEK293T cells, and occupancy at the STAT3 binding site in the XRCC1 promoter is similarly low (Figure 6). This conditional regulation may explain why the promoter assay shows stable output between -612 and -310 , despite the STAT3 site being deleted in the -310 construct (Figure 1 and Supplementary Materials Figure S1).

shRNA-mediated knockdown of STAT3 significantly reduced both the gene and protein expression of XRCC1 (Figure 3). Importantly, it also reduced the occupancy at the STAT3 binding site within the XRCC1 promoter in MDA-231 cells (Figure 2C). We further confirmed the dependence on activated, phosphorylated STAT3 (Y705) by chemical inhibition with alantolactone. Alantolactone targets the SH2 domain of STAT3 and prevents phosphorylation at Y705 [48]. In the presence of $15 \mu \mathrm{M}$ alantolactone, we again showed a significant reduction in both the gene and protein expression of XRCC1 (Figure 5 and Supplementary Materials Figure S3).

Given that TNBC cell lines showed higher levels of pSTAT3, we examined physiologically relevant stimuli that could lead to activated STAT3 and increased XRCC1 expression. Several reports have demonstrated that inflammatory signaling through IL-6R promotes constitutive activation in TNBC $[47,49,50]$. These signaling events are proposed to play a role in breast cancer development and progression through aberrant signaling [47]. Using IL-6, we demonstrated that STAT3 is activated in HEK293T and MDA-231 and subsequently increases the gene and protein expression of XRCC1 (Figures 7 and 8). More importantly, we showed that IL-6 increased the occupancy of STAT3 at the STAT3 binding site within the HEK293T XRCC1 promoter, which showed low occupancy under normal growth conditions (Figure 8).

These data provide evidence that STAT3 is a conditional regulator of XRCC1 in response to stress and inflammatory signals. Under normal physiological conditions, activation of STAT3 is tightly controlled by several intrinsic inhibitors, including protein tyrosine phosphatases, the suppressors of cytokine signaling, and the protein inhibitor of activated STAT [42]. These regulatory mechanisms allow STAT3 to exert its physiological functions and limit the aberrant signaling seen in cancer. The low level of STAT3 and PSTAT3 in the HEK293T cells confirm the tightly checked role of STAT3 in these nontumorigenic cells and also that XRCC1 expression is not driven by STAT3 in this cell line (Figure 6). Interestingly, the ectopic overexpression of STAT3 increased the levels of pSTAT3 and the occupancy of STAT3 at the XRCC1 promoter in HEK293T but did not increase the expression of XRCC1 
(1 vs. 1.03, Figure 6). However, after stimulation with IL-6, we see a dramatic increase in the presence of activated pSTAT3 and increased XRCC1 protein and gene expression (Figure 8). Therefore, the expression and activation of STAT3 alone is not enough to stimulate the transcription of XRCC1 in this nontumorigenic cell line.

Transformation involves numerous cellular and genomic changes that reduce inhibitions on growth and proliferation signals. These changes also reduce apoptotic signaling, cell cycle control mechanisms and alter DNA damage response. As a result, we see overexpression of STAT3 being sufficient to drive XRCC1 expression in MDA-231 cells (Figure 4), as well as stimulation by IL-6 and EGF (Figure 7 and Supplementary Materials Figure S5). These results are consistent with two recent studies, which examined the role STAT3 plays in regulating growth and invasion in TNBC cell lines [51,52]. Both studies used CHiP-seq to examine the transcriptional regulation of genes by STAT3. While their focus was on proliferation, migration and invasion genes, examination of the CHiP-seq results (GSE85579 and GSE152203) at the XRCC1 promoter showed STAT3 binding sites within the MDA-MB231, MDA-MB-468, and HCC70 cells [51,52]. These CHiP-seq results in basal-like TNBC cell lines support our findings of higher expression and activation of STAT3 resulting in increased XRCC1 expression [11,51,52]. Further validation of the pSTAT3 dependence of these sites is needed to better understand the impact of the conditional regulation of XRCC1 by pSTAT3 in TNBC.

The more blunted response in HEK293T cells and reports of under-expression of XRCC1 in hormone-positive breast cancers suggest that activated STAT3 regulation of XRCC1 may be highly tissue specific and dependent on exogenous signals like IL-6 or EGF [27]. This tissue specificity is supported by the finding that stimulation by IL-6 is more robust than ectopic expression alone ( 3-fold vs. 2-fold) in HEK293T. The difference in expression from IL-6 vs. ectopic STAT3 may be related to the downregulation of inhibiting factors such as SOCS3 or could reflect the additional changes in redox balance and reactive species induced by IL-6 [47,53-55]. Additional studies are needed to differentiate these contributors in the STAT3-related transcriptional control of XRCC1, although, in all likelihood, these mechanisms are probably inter-related.

In TNBC, IL-6 plays a critical role in breast cancer growth and maintenance $[47,55,56]$. TNBC tumor cells can autonomously produce IL-6, resulting in the constitutive activation of STAT3 [55,56]. Activated STAT3 acts as a transcription factor controlling the expression of genes involved in regulating cell proliferation, anti-apoptosis, migration, invasion, angiogenesis, chemoresistance, immune escape, and autophagy [43]. Here, for the first time, we have linked STAT3 activation by cytokines and stress factors to the regulation of a DNA repair protein, XRCC1. In our previous work with TNBC cell lines, we noted the overexpression of XRCC1 in pre-clinical TNBC cell lines, which contrasted with previous reports on hormone-positive breast cancers noting a deficiency in XRCC1 expression [11,14,27,30]. By examining the effects of XRCC1 over-expression, we noted resistance of the alkylating agents to MMS in highly over-expressed XRCC1 cell lines. Other reports have associated the upregulation of XRCC1 with increased risk of breast cancer; poor survival across low and high-risk breast cancer subtypes; increased tumor aggressiveness; and resistance to cisplatin, PARP inhibitors, and ionizing radiation $[9,26,27,57]$. However, the mechanism driving the overexpression of XRCC1 in TNBC and other cell lines has not been identified.

We were able to reverse MMS resistance through shRNA-mediated knockdown of XRCC1 expression [11]. Additionally, the under-expression of XRCC1, seen in some hormone-positive breast cancers, is correlated with increased sensitivity to chemotherapeutics, including ionizing radiation, cisplatin, and PARP inhibitors [14,26,27,35]. Together, these results suggest that attenuation of XRCC1 expression influences breast cancer etiology and response to therapy. While we have identified pSTAT3 as a novel regulator of XRCC1 in TNBC, it is also likely that activated STAT3 regulates XRCC1 under stress and growth conditions in nontumorigenic cells. However, it is not until pSTAT3 levels become dysregulated that sustained increases in XRCC1 expression and subsequently changes in BER and SSBR would be observed, contributing to chemoresistance and tumor 
aggressiveness. The constitutive activation of STAT3 in TNBC allowed this regulation to be identified more readily.

This work illuminates the complex regulatory mechanisms of BER proteins like XRCC1. Dysregulation of DNA repair proteins is a hallmark of cancer, yet basal and stress-induced regulatory mechanisms for these proteins are poorly delineated [38,39]. Here, we have identified a stress-specific regulatory mechanism for increasing the protein levels of XRCC1, which becomes dysregulated in TNBC and potentially other cancers.

\section{Materials and Methods}

\subsection{Cell Culture}

MDA-MB-231(MDA-231), MDA-MB-468 (MDA-468), and HEK293T were purchased from the American Type Culture Collection (ATCC HTB-26, HTB-132, and CRL-3216, respectively; Manassas, VA, USA) within the last 24 months and passaged $<15$ times for all experiments. Cells were tested biweekly during experiments for mycoplasma contamination using the Lonza MycoAlert ${ }^{\circledR}$ (Lonza \#LT07-318). MDA-231 and MDA-468 cells were grown in DMEM High Glucose + GlutaMAX ${ }^{\mathrm{TM}}$ (Life Technologies, Carlsbad, CA, USA, $\# 10566016$ ) and supplemented with 1\% sodium pyruvate (Life Technologies, \#11360070) and $10 \%$ FBS (Premium Select, R\&D systems, Minneapolis, MN, USA). HEK293T cells were grown in DMEM High Glucose + L-Glutamine (HyClone, Logan, UT, USA, \# SH30022.01) and supplemented with 1\% sodium pyruvate (Life Technologies \#11360070) and 10\% FBS. Cells were maintained in a humidified $37^{\circ} \mathrm{C}$ incubator with $5 \%$ carbon dioxide.

\subsection{Promoter Luciferase Assay}

Transcriptional activity at the XRCC1 promoter was measured using a dual promoterluciferase assay similar to Chen et al. [32]. The pGL3 plasmid containing the full-length $X R C C 1$ promoter from Chen et al. was provided by Dr. Charles Lopez (Oregon Health Sciences University, Portland, OR, USA). XRCC1 promoter fragments XRCC1, $\Delta 766, \Delta 612$, $\triangle 310$, and $\Delta 35$ were cloned using XRCC1 promoter-specific primers (Table 1 ) from genomic DNA harvested from MDA-231 cells. Promoter PCR fragments were digested with Nhel Anza $^{\mathrm{TM}}$ (Thermo Fisher Scientific, Waltham, MA, USA, \#IVGN0066) and NcoI Anza ${ }^{\mathrm{TM}}$ (Thermo Fisher Scientific\#IVGN0026) and then ligated into a pGL3 plasmid backbone with Anza $^{\mathrm{TM}}$ T4 DNA Ligase (Thermo Fisher Scientific \#IVGN2104). The final plasmid constructs with the correct promoter fragment insertion were confirmed by Sanger sequencing by Eurofins. MDA-231 cells were transfected with $0.4 \mu \mathrm{g}$ of plasmid DNA and $0.1 \mu \mathrm{g}$ of pRSV $\beta$ galactosidase plasmid DNA using Jetprime (Polyplus transfection, New York, NY, USA, $\# 114-15,1: 6)$. HEK293T cells were transfected with $0.4 \mu \mathrm{g}$ of plasmid DNA and $0.1 \mu \mathrm{g}$ of pRSV $\beta$ galactosidase plasmid DNA (Promega, Madison, WI, USA) using Jetprime transfection reagent (1:2). pGL3 was used as a negative control to ensure the assay was working correctly. Using the $\beta$-Galactosidase Enzyme Assay System with Reporter Lysis Buffer (Promega \#E2000) and the Luciferase Assay System (Promega \#E1500), transfected cells were lysed $24 \mathrm{~h}$ after transfection, and luminescence and absorbance were collected using an Infinite ${ }^{\circledR}$ M1000 PRO, TECAN (Mannedorf, Switzerland). Luminescence values were normalized to the respective $\beta$-galactosidase absorbance to control for transfection efficiency. The assay was performed in parallel plates in technical triplicate over three biological replicates. Results represent the average of the three biological replicates \pm standard error of the mean (SEM). 
Table 1. Promoters for luciferase assay cloning.

\begin{tabular}{cc}
\hline Primer & Sequence \\
\hline XRCC1 Full Length Forward & CTTACGCGTGCTAGCGGACGCAGAACCC \\
XRCC1 Full Length Reverse & GCGTCTTCCATGGTCACCGAGTCCTGGCTGC \\
XRCC1 $\Delta 766$ Forward & CTTACGCGTGCTAGCGCAAGGGGACAGAGAGAAGAG \\
XRCC1 $\Delta 612$ Forward & CTTACGCGTGCTAGCGAGGCCGAGGCAGGTGGATC \\
XRCC1 $\Delta 310$ Forward & CTTACGCGTGCTAGCGGATTTGCTTTCTCGGCTTC \\
XRCC $1 \Delta 35$ Forward & CTTACGCGTGCTAGCGGCCGGGGTTTGAAAGGC \\
\hline
\end{tabular}

\subsection{Promoter Binding ELISA}

Potential transcription factors binding the XRCC1 promoter were identified using the transcription factor binding array (Signosis Santa Clara, CA, USA \#FA-1001-NE). Following the manufacturers' instructions. Nuclear extracts were isolated from MDA-231, and the binding of transcription factors was tested using the XRCC1 full length and XRCC1 $\triangle 35$ PCR products described in the promoter luciferase sections, with the primers detailed in Table 1. The promoter binding ELISA was performed with two biological replicates, using Sp1 as a positive binding control.

\subsection{Chromatin Immunoprecipitation (ChIP)}

MDA-231, MDA-468, and HEK293T cells were grown to confluency in a $150 \mathrm{~mm}$ dish. The cells were crosslinked by the addition of $1 \%$ formaldehyde in DMEM with gentle rocking at room temperature $\left(\mathrm{RT} \sim 23{ }^{\circ} \mathrm{C}\right.$ ) for $8-10 \mathrm{~min}$. Then, $0.1 \mathrm{M}$ glycine was added for $5 \mathrm{~min}$ at RT to quench the formaldehyde. The cells were washed with cold $1 \times$ phosphate-buffered saline (PBS) and subsequently lysed with $1 \mathrm{~mL}$ of farnham lysis buffer (5 mM HEPES pH 8.0, $85 \mathrm{mM} \mathrm{KCl}$. 0.5\% NP-40) for $20 \mathrm{~min}$ on ice, then pelleted by centrifugation at $2000 \mathrm{rpm}$ and resuspended in RIPA buffer (50mM Tris- $\mathrm{HCl} \mathrm{pH} 8$, $150 \mathrm{mM} \mathrm{NaCl}, 1 \%$ sodium deoxycholate, $1 \mathrm{mM}$ EDTA, $0.1 \%$ SDS, $1 \%$ Triton X-100) for $20 \mathrm{~min}$. Isolated chromatin was then sonicated on ice at an amplitude of 12 on a Misonix S-4000 with $15 \mathrm{~s}$ on $/ 50 \mathrm{~s}$ off for a total process time of $2.5 \mathrm{~min}$ for MDA-231 and MDA468 and amplitude of 10 on a Misonix S-4000 with $15 \mathrm{~s}$ on/50 s off for a total process time of $3.5 \mathrm{~min}$ for HEK293T. Chromatin was incubated overnight at $4{ }^{\circ} \mathrm{C}$ on a rotator using an anti-STAT3 antibody diluted to manufactures' recommendations for chromatin immunoprecipitation (Cell Signaling Technology, Danvers, MA, USA \#9131S), an anti-Sp1 antibody (Abcam Cambridge, MA, USA \#ab13370) diluted 1:100 as a positive control, a mouse IgG isotype control (Cell Signaling Technology \#5415S) and with Protein A/G magnetic beads (Thermo Fisher Scientific \#88802). Magnetic beads were washed with cold LiCl wash buffer (100 mM Tris- $\mathrm{HCl}, 500 \mathrm{mM} \mathrm{LiCl}, 1 \% \mathrm{NP}-40,1 \%$ Triton X-100) and TE Buffer (10mM Tris-HCl pH 7.5, 0.1mM EDTA). Proteinase K (VWR Life Science Radnor, PA, USA \# E195-5ML) was then added with ChIP Elution Buffer (1\% SDS, $0.1 \mathrm{M} \mathrm{NaHCO}_{3}$ ) and incubated at $65{ }^{\circ} \mathrm{C} 950 \mathrm{rpm}$ for $2 \mathrm{~h}$. Proteinase $\mathrm{K}$ was then inactivated at $90^{\circ} \mathrm{C}$ for $10 \mathrm{~min}$. DNA was purified using a PureLink PCR Purification Kit (Life Technologies \#K310002 kit). $\mathrm{An} \mathrm{IgV}$ browser was used to design primers examining the occupancy across the XRCC1 promoter (Table 2). 
Table 2. Chromatin Immunoprecipitation primers.

\begin{tabular}{cc}
\hline Primer & Sequence \\
\hline XRCC1 -564 to -457 Forward & TGGGCAACATGGCAAGA \\
XRCC $1-564$ to -457 Reverse & CTCCTAAGTAGCTGGGATTACAC \\
XRCC1 -452 to -358 Forward & AGTGGGAGGATCCCTTGG \\
XRCC $1-452$ to -358 Reverse & ACAGGGTCTTGCTCTCTCA \\
XRCC1 -312 to -236 Forward & AAAGATTTGCTTTCTCGGCTTC \\
XRCC1 -312 to -236 Reverse & CAGTCGCGCCTCTCTTC \\
XRCC1 -251 to -110 Forward & TTTCTTCCAGACACCAATCCC \\
XRCC1 -251 to -110 Reverse & TAGCAACGAGCGTTTCCTC \\
XRCC1 -127 to -16 Forward & AGGAAACGCTCGTTGCTAA \\
XRCC1 -127 to -16 Reverse & TCGGGCCTTTCAAACCC \\
XRCC1 SP1 Site Forward [33] & ATTGGGAGGCGAGGCTA \\
XRCC1 SP1 Site Reverse [33] & TCTCCAGAGCGGGAAGAG \\
\hline
\end{tabular}

\subsection{Modulated Expression of STAT3}

Plasmid constructs for stable depletion of human STAT3 mRNA, pSIH-puro-STAT3 shRNA (referred two as shRNA \#1), and its control were gifts from Frank Sinicrope (Addgene plasmid \#26596 and \#26597; Watertown, MA, USA). An additional shRNA construct specific for STAT3 (shRNA Clone ID:NM_003150.3-458s21c1 referred to as shRNA \#2 hereafter) and its pLKO.1 control were purchased from Sigma-Aldrich (St. Louis, MO, USA). Both shRNA constructs and their controls were used to validate the STAT3 binding site and expression changes. MDA-231 cells were plated at 200,000 cells/well in a 6-well culture plate. After $48 \mathrm{~h}$, cells were transfected with $5 \mu \mathrm{g}$ plasmid DNA (shRNA\# 1 or 2 or appropriate vector control) and FuGene 6 (Promega) at a 1:6 ratio (DNA to FuGene). Cells were allowed to recover for $48 \mathrm{~h}$ following transfection. STAT3 was overexpressed using a pcDNA3.1+ STAT3 ORF clone from Genscript (Piscataway, NJ, USA) that has a Cterminal Flag-tag. MDA-231 cells were plated at 200,000 cells/well in a 6-well culture plate, and HEK293T were plated in $10 \mathrm{~cm}$ plates at 500,000 cells/plate. After 48h, MDA-231 cells were transfected with $5 \mu \mathrm{g}$ of plasmid DNA (STAT3-FLAG and proper vector control) and Fugene 6 (Promega) in a 1:6 ratio (DNA to Fugene). HEK239T cells were transfected with $10 \mu \mathrm{g}$ of plasmid DNA (STAT3-FLAG and proper vector control) and Jetprime transfection agent at a 1:2 ratio (DNA to Jetprime). $48 \mathrm{~h}$ post-transfection, cells were rinsed with $1 \times \mathrm{PBS}$, plates were scraped, and the pelleted cells were stored overnight in $-80^{\circ} \mathrm{C}$. Immunoblot was then performed as described below.

\subsection{Gene Expression and $q P C R$}

Relative gene expression was performed through mRNA isolation from MDA-231, MDA-468, and HEK293T cell lines using Invitrogen Cell to $C_{t}$ kit (Life Technolgoies \#4399002). Following the manufacturers' recommendations, the cells were plated in a 96-well plate, and the untreated cells were grown to $75 \%$ confluency. For transfection, $0.1 \mu \mathrm{g}$ of plasmid DNA was added with Fugene 6 transfection reagent in a 1:6 ratio (plasmid DNA to Fugene). Cells were then allowed $48 \mathrm{~h}$ to recover before being lysed for mRNA isolation using an Invitrogen Cell to $C_{t}$ kit (Life Technologies \#4399002). The cells were then lysed, and RT-PCR was performed to produce cDNA using the reagents from the kit. After cDNA synthesis, qPCR was performed using TaqMan Gene expression primers (Table 3) and the TaqMan master mix provided with the kit (Applied Biosystems Foster City, CA, USA \#4369016). The assay was performed in technical triplicate over three biological replicates. Results represent the average of the three biological replicates \pm standard error of the mean (SEM). 
Table 3. TaqMan primers.

\begin{tabular}{cc}
\hline Gene & Primer \\
\hline XRCC1 & Hs00959834_m1 FAM \\
STAT3 & Hs00374280_m1 FAM \\
ACTIN & Hs01060665_g1 VIC \\
\hline
\end{tabular}

\subsection{Cytokine Exposure}

Cytokine exposure was performed using recombinant Human IL-6 protein (R\&D Systems, Minneapolis, MN, USA, \#206-IL-010/CF). IL-6 was aliquoted in PBS at a concentration of $100 \mu \mathrm{g} / \mathrm{mL}$ and stored at $-80^{\circ} \mathrm{C}$ for no longer than 3 months before use, as recommended by the manufacturers. Aliquoted IL- 6 was added to the cell culture medium to a final concentration of 50ng/mL. MDA-231 and HEK293T cells were plated in $15 \mathrm{~mm}$ dishes and cultured to $70-80 \%$ confluency. Cells were then exposed to IL- 6 at a final concentration of $50 \mathrm{ng} / \mathrm{mL}$ for $30 \mathrm{~min}, 1$, and $4 \mathrm{~h}$. Cells rinsed with 1 X PBS plates were scraped, and pelleted cells were stored overnight in $-80^{\circ} \mathrm{C}$. Immunoblot was performed as described below.

\subsection{Immunoblot}

Immunoblot was performed as described previously [11]. Briefly, the cells were grown in $150 \mathrm{~mm}$ dishes and cultured to $70-80 \%$ confluence. Cells were rinsed with PBS, scraped, stored overnight at $-80^{\circ} \mathrm{C}$, then lysed. Protein content was quantified using a Bradford assay. Then, $20 \mu \mathrm{g}$ of lysate was separated on $7.5 \%$ or $4-15 \%$ SDS Page gel (Bio-Rad \#s, 4561025 and 4561084) and transferred to a nitrocellulose membrane. Membranes were blocked in 5\% non-fat dry milk in Tris-buffered saline (VWR \#J640-4L) containing $0.1 \%$ Tween 20 (Thermo Fisher Scientific \#BP337, TBS-T) and raised against the following primary antibodies: XRCC1 (1:1000 \#MS434P1) from Fisher Scientific (Pittsburgh, PA, USA); STAT3 (1:1000, \#9139) and pSTAT3 Y705 (1:500, \#9131) from Cell Signaling Technology, Inc.; and $\alpha$-tubulin (1:5000, \#T9026) from Millipore Sigma (St. Louis, MO, USA) summarized in Table 4 . The blots were incubated with either of the horseradish peroxidase (HRP)-labeled secondary antibodies: goat anti-rabbit-HRP or goat anti-mouse-HRP (\#7074P2 and \#7076S respectively) from Cell Signaling Technology, Inc. HRP antibody target proteins were detected by incubating with WesternBright Sirius (Advansta San Jose, CA, USA \#K-12043D20). All immunoblotting was conducted with three biological replicates. Where indicated, protein quantification was conducted with Image Lab Software (Bio-Rad, Hercules, CA, USA). Band intensity was normalized to loading controls and averaged over the three biological replicates with SEM presented.

Table 4. Antibodies and dilutions used for immunoblotting experiments.

\begin{tabular}{cc}
\hline Antibody & Dilution \\
\hline XRCC1 (Fisher Scientific \#MS434P1) & $1: 1000$ \\
STAT3 (Cell Signaling Technology \#9139) & $1: 1000$ \\
Alpha-Tubulin (Sigma Aldrich \#T9026) & $1: 5000$ \\
pSTAT3 Y705 (Cell Signaling Technology \#9131) & $1: 500$ \\
\hline
\end{tabular}

\subsection{Statistical Analysis}

Assays were performed as three biological replications. One-way ANOVA and means were compared with Dunnett's post hoc analysis. Comparison groups are indicated in graphs. All means are reported \pm SEM.

\section{Conclusions}

Here, we demonstrated that activation of STAT3 through cytokine stimulation or ectopic overexpression stimulated the expression of XRCC1. Further, we confirmed a binding site for STAT3 within the XRCC1 promoter with higher occupancy in triple negative 
breast cancer cell lines than in the nontumorigenic HEK293T. Together, these data indicate that activated STAT3 regulates XRCC1 expression, and constitutive activation of STAT3 leads to dysregulated expression of XRCC1. The consequences of this dysregulation need more investigation but likely lead to BER dysfunction, which we have previously observed in triple negative breast cancers [11].

Supplementary Materials: The following are available online at https: / www.mdpi.com/article / 10.3390/ijms22115475/s1, Figure S1: XRCC1 promoter expression in HEK293T cells has actively transcribed regions between -612 and -35 ; Figure S2: Promoter binding ELISA identifies STAT3 as a positive binder to the XRCC1 promoter; Figure S3: Chemical inhibition of the phosphorylation of STAT3 at Y705 by alantolactone decreases the expression of XRCC1 in MDA-231 at 4 and $24 \mathrm{~h}$; Figure S4: Immunoblotting of cell lines MDA-231, MDA-468 and HEK293T; Figure S5:EGF increases phospho-STAT3 and increases the expression of XRCC1 in MDA-231.

Author Contributions: Conceptualization, G.W. and N.R.G.; methodology, G.W., M.S., and N.R.G.; formal analysis, G.W. and N.R.G.; resources, G.W., M.S., and N.R.G., data curation, G.W. and N.R.G.; writing-original draft preparation, G.W., M.S., and N.R.G.; writing-review and editing, G.W., M.S., and N.R.G.; supervision, N.R.G.; project administration, N.R.G.; funding acquisition, N.R.G. All authors have read and agreed to the published version of the manuscript.

Funding: This work was supported by an Innovation Award from the Breast Cancer Research Foundation of Alabama to N.R.G and the Dean's predoctoral fellowship to G.W. from the University of South Alabama College of Medicine.

Institutional Review Board Statement: Not applicable.

Informed Consent Statement: Not applicable.

Data Availability Statement: All data is contained within the manuscript.

Acknowledgments: The authors would like to thank Lana Vukadin for her assistance in establishing the ChIP assay. They would also like to thank Leslyn Hanakahi for her helpful comments on the manuscript.

Conflicts of Interest: The authors declare no conflict of interest.

\section{References}

1. Caldecott, K.W. DNA single-strand break repair. Exp. Cell Res. 2014, 329, 2-8. [CrossRef] [PubMed]

2. Wilson, S.H.; Kunkel, T.A. Passing the baton in base excision repair. Nat. Genet. 2000, 7, 176-178. [CrossRef]

3. Audebert, M.; Salles, B.; Calsou, P. Involvement of Poly(ADP-ribose) Polymerase-1 and XRCC1/DNA Ligase III in an Alternative Route for DNA Double-strand Breaks Rejoining. J. Biol. Chem. 2004, 279, 55117-55126. [CrossRef]

4. Frit, P.; Barboule, N.; Yuan, Y.; Gomez, D.; Calsou, P. Alternative end-joining pathway(s): Bricolage at DNA breaks. DNA Repair 2014, 17, 81-97. [CrossRef] [PubMed]

5. Mladenov, E.; Iliakis, G. Induction and repair of DNA double strand breaks: The increasing spectrum of non-homologous end joining pathways. Mutat. Res. Mol. Mech. Mutagen. 2011, 711, 61-72. [CrossRef]

6. Moser, J.; Kool, H.; Giakzidis, I.; Caldecott, K.; Mullenders, L.H.; Fousteri, M.I. Sealing of Chromosomal DNA Nicks during Nucleotide Excision Repair Requires XRCC1 and DNA Ligase III $\alpha$ in a Cell-Cycle-Specific Manner. Mol. Cell 2007, 27, 311-323. [CrossRef]

7. Narciso, L.; Fortini, P.; Pajalunga, D.; Franchitto, A.; Liu, P.; Degan, P.; Frechet, M.; Demple, B.; Crescenzi, M.; Dogliotti, E. Terminally differentiated muscle cells are defective in base excision DNA repair and hypersensitive to oxygen injury. Proc. Natl. Acad. Sci. USA 2007, 104, 17010-17015. [CrossRef]

8. Sykora, P.; Yang, J.-L.; Ferrarelli, L.K.; Tian, J.; Tadokoro, T.; Kulkarni, A.; Weissman, L.; Keijzers, G.; Wilson, D.M.; Mattson, M.P.; et al. Modulation of DNA base excision repair during neuronal differentiation. Neurobiol. Aging 2013, 34, $1717-1727$. [CrossRef]

9. Tebbs, R.S.; Flannery, M.L.; Meneses, J.J.; Hartmannc, A.; Tucker, J.D.; Thompson, L.H.; Cleaver, J.E.; Pedersen, R.A. Requirement for theXrcc1DNA Base Excision Repair Gene during Early Mouse Development. Dev. Biol. 1999, 208, 513-529. [CrossRef]

10. Horton, J.K.; Gassman, N.R.; Dunigan, B.D.; Stefanick, D.F.; Wilson, S.H. DNA polymerase $\beta$-dependent cell survival independent of XRCC1 expression. DNA Repair 2015, 26, 23-29. [CrossRef]

11. Lee, K.J.; Piett, C.G.; Andrews, J.F.; Mann, E.; Nagel, Z.D.; Gassman, N.R. Defective base excision repair in the response to DNA damaging agents in triple negative breast cancer. PLoS ONE 2019, 14, e0223725. [CrossRef] [PubMed]

12. Ali, R.; Alabdullah, M.; Alblihy, A.; Miligy, I.; Mesquita, K.A.; Chan, S.Y.; Moseley, P.; Rakha, E.A.; Madhusudan, S. PARP1 blockade is synthetically lethal in XRCC1 deficient sporadic epithelial ovarian cancers. Cancer Lett. 2020, 469, 124-133. [CrossRef] 
13. Ali, R.; Alblihy, A.; Toss, M.S.; Algethami, M.; Al Sunni, R.; Green, A.R.; Rakha, E.A.; Madhusudan, S. XRCC1 deficient triple negative breast cancers are sensitive to ATR, ATM and Wee1 inhibitor either alone or in combination with olaparib. Ther. Adv. Med. Oncol. 2020, 12. [CrossRef] [PubMed]

14. Ali, R.; Al-Kawaz, A.; Toss, M.S.; Green, A.R.; Miligy, I.M.; Mesquita, K.A.; Seedhouse, C.; Mirza, S.; Band, V.A.; Rakha, E.; et al. Targeting PARP1 in XRCC1-Deficient Sporadic Invasive Breast Cancer or Preinvasive Ductal Carcinoma In Situ Induces Synthetic Lethality and Chemoprevention. Cancer Res. 2018, 78, 6818-6827. [CrossRef] [PubMed]

15. Sizova, D.V.; Keh, A.; Taylor, B.F.; Sweasy, J.B. The R280H X-ray cross-complementing 1 germline variant induces genomic instability and cellular transformation. DNA Repair 2015, 31, 73-79. [CrossRef] [PubMed]

16. El-Khamisy, S.F.; Masutani, M.; Suzuki, H.; Caldecott, K.W. A requirement for PARP-1 for the assembly or stability of XRCC1 nuclear foci at sites of oxidative DNA damage. Nucleic Acids Res. 2003, 31, 5526-5533. [CrossRef]

17. Hoch, N.C.; Hanzlikova, H.; Rulten, S.L.; Tétreault, M.; Koumulainen, E.; Ju, L.; Hornyak, P.; Zeng, Z.; Gittens, W.; Rey, S.A.; et al. XRCC1 mutation is associated with PARP1 hyperactivation and cerebellar ataxia. Nat. Cell Biol. 2017, 541, 87-91. [CrossRef]

18. Taylor, R.M.; Thistlethwaite, A.; Caldecott, K.W. Central Role for the XRCC1 BRCT I Domain in Mammalian DNA Single-Strand Break Repair. Mol. Cell. Biol. 2002, 22, 2556-2563. [CrossRef]

19. Brem, R.; Hall, J. XRCC1 is required for DNA single-strand break repair in human cells. Nucleic Acids Res. 2005, 33, 2512-2520. [CrossRef]

20. Horton, J.K.; Watson, M.; Stefanick, D.F.; Shaughnessy, D.T.; Taylor, A.J.; Wilson, S.H. XRCC1 and DNA polymerase $\beta$ in cellular protection against cytotoxic DNA single-strand breaks. Cell Res. 2008, 18, 48-63. [CrossRef]

21. Horton, J.K.; Stefanick, D.F.; Gassman, N.R.; Williams, J.G.; Gabel, S.A.; Cuneo, M.J.; Prasad, R.; Kedar, P.S.; Derose, E.F.; Hou, E.W.; et al. Preventing oxidation of cellular XRCC1 affects PARP-mediated DNA damage responses. DNA Repair 2013, 12, 774-785. [CrossRef]

22. Gassman, N.R.; Wilson, S.H. Micro-irradiation tools to visualize base excision repair and single-strand break repair. DNA Repair 2015, 31, 52-63. [CrossRef]

23. Abdel-Fatah, T.; Sultana, R.; Abbotts, R.; Hawkes, C.; Seedhouse, C.; Chan, S.; Madhusudan, S. Clinicopathological and functional significance of XRCC1 expression in ovarian cancer. Int. J. Cancer 2012, 132, 2778-2786. [CrossRef] [PubMed]

24. Xu, W.; Chen, Q.; Wang, Q.; Sun, Y.; Wang, S.; Li, A.; Xu, S.; Røe, O.D.; Wang, M.; Zhang, R.; et al. JWA reverses cisplatin resistance via the CK2-XRCC1 pathway in human gastric cancer cells. Cell Death Dis. 2014, 5, e1551. [CrossRef] [PubMed]

25. Wu, Z.; Miao, X.; Zhang, Y.; Li, D.; Zou, Q.; Yuan, Y.; Liu, R.; Yang, Z. XRCC1 Is a Promising Predictive Biomarker and Facilitates Chemo-Resistance in Gallbladder Cancer. Front. Mol. Biosci. 2020, 7, 70. [CrossRef] [PubMed]

26. De Summa, S.; Pinto, R.; Pilato, B.; Sambiasi, D.; Porcelli, L.; Guida, G.; Mattioli, E.; Paradiso, A.; Merla, G.; Micale, L.; et al. Expression of base excision repair key factors and miR17 in familial and sporadic breast cancer. Cell Death Dis. 2014, 5, e1076. [CrossRef] [PubMed]

27. Sultana, R.; Abdel-Fatah, T.; Abbotts, R.; Hawkes, C.; Albarakati, N.; Seedhouse, C.; Ball, G.; Chan, S.; Rakha, E.A.; Ellis, I.O.; et al. Targeting XRCC1 Deficiency in Breast Cancer for Personalized Therapy. Cancer Res. 2013, 73, 1621-1634. [CrossRef] [PubMed]

28. Karahalil, B.; Bohr, V.; Wilson, I.D. Impact of DNA polymorphisms in key DNA base excision repair proteins on cancer risk. Hum. Exp. Toxicol. 2012, 31, 981-1005. [CrossRef]

29. Chandrashekar, D.S.; Bashel, B.; Balasubramanya, S.A.H.; Creighton, C.J.; Ponce-Rodriguez, I.; Chakravarthi, B.V.; Varambally, S. UALCAN: A Portal for Facilitating Tumor Subgroup Gene Expression and Survival Analyses. Neoplasia 2017, 19, 649-658. [CrossRef]

30. Lee, K.J.; Mann, E.; Wright, G.; Piett, C.G.; Nagel, Z.D.; Gassman, N.R. Exploiting DNA repair defects in triple negative breast cancer to improve cell killing. Ther. Adv. Med. Oncol. 2020, 12. [CrossRef]

31. Chavez, K.J.; Garimella, S.V.; Lipkowitz, S. Triple negative breast cancer cell lines: One tool in the search for better treatment of triple negative breast cancer. Breast Dis. 2011, 32, 35-48. [CrossRef]

32. Chen, D.; Yu, Z.; Zhu, Z.; Lopez, C.D. E2F1 Regulates the Base Excision Repair Gene XRCC1 and Promotes DNA Repair. J. Biol. Chem. 2008, 283, 15381-15389. [CrossRef] [PubMed]

33. Fletcher, S.C.; Grou, C.P.; Legrand, A.J.; Chen, X.; Söderström, K.; Poletto, M.; Dianov, G.L. Sp1 phosphorylation by ATM downregulates BER and promotes cell elimination in response to persistent DNA damage. Nucleic Acids Res. 2017, 46, 1834-1846. [CrossRef] [PubMed]

34. Alli, E.; Sharma, V.B.; Sunderesakumar, P.; Ford, J.M. Defective Repair of Oxidative DNA Damage in Triple-Negative Breast Cancer Confers Sensitivity to Inhibition of Poly(ADP-Ribose) Polymerase. Cancer Res. 2009, 69, 3589-3596. [CrossRef] [PubMed]

35. Wolf, D.M.; Yau, C.; Sanil, A.; Glas, A.; Petricoin, E.; Wulfkuhle, J.; Severson, T.M.; Linn, S.; Brown-Swigart, L.; Hirst, G.; et al. DNA repair deficiency biomarkers and the 70-gene ultra-high risk signature as predictors of veliparib/carboplatin response in the I-SPY 2 breast cancer trial. npj Breast Cancer 2017, 3, 1-9. [CrossRef]

36. Xu, W.; Wang, S.; Chen, Q.; Zhang, Y.; Ni, P.; Wu, X.; Zhang, J.; Qiang, F.; Li, A.; Røe, O.D.; et al. TXNL1-XRCC1 pathway regulates cisplatin-induced cell death and contributes to resistance in human gastric cancer. Cell Death Dis. 2014, 5, e1055. [CrossRef] [PubMed]

37. Sak, S.C.; Harnden, P.; Johnston, C.F.; Paul, A.B.; Kiltie, A.E. APE1 and XRCC1 Protein Expression Levels Predict Cancer-Specific Survival Following Radical Radiotherapy in Bladder Cancer. Clin. Cancer Res. 2005, 11, 6205-6211. [CrossRef] 
38. Christmann, M.; Kaina, B. Transcriptional regulation of human DNA repair genes following genotoxic stress: Trigger mechanisms, inducible responses and genotoxic adaptation. Nucleic Acids Res. 2013, 41, 8403-8420. [CrossRef]

39. Wright, G.; Gassman, N.R. Transcriptional dysregulation of base excision repair proteins in breast cancer. DNA Repair 2020, 93, 102922. [CrossRef]

40. Loh, C.-Y.; Arya, A.; Naema, A.F.; Wong, W.F.; Sethi, G.; Looi, C.Y. Signal Transducer and Activator of Transcription (STATs) Proteins in Cancer and Inflammation: Functions and Therapeutic Implication. Front. Oncol. 2019, 9, 48. [CrossRef]

41. Huynh, J.; Chand, A.; Gough, D.; Ernst, M. Therapeutically exploiting STAT3 activity in cancer using tissue repair as a road map. Nat. Rev. Cancer 2019, 19, 82-96. [CrossRef]

42. Guanizo, A.C.; Fernando, C.D.; Garama, D.J.; Gough, D.J. STAT3: A multifaceted oncoprotein. Growth Factors 2018, $36,1-14$. [CrossRef]

43. Qin, J.-J.; Yan, L.; Zhang, J.; Zhang, W.-D. STAT3 as a potential therapeutic target in triple negative breast cancer: A systematic review. J. Exp. Clin. Cancer Res. 2019, 38, 1-16. [CrossRef]

44. Gearing, L.J.; Cumming, H.E.; Chapman, R.; Finkel, A.M.; Woodhouse, I.B.; Luu, K.; Gould, J.A.; Forster, S.C.; Hertzog, P.J CiiiDER: A tool for predicting and analysing transcription factor binding sites. PLoS ONE 2019, 14, e0215495. [CrossRef]

45. Banerjee, K.; Resat, H. Constitutive activation of STAT3 in breast cancer cells: A review. Int. J. Cancer 2016, 138, 2570-2578. [CrossRef] [PubMed]

46. Sirkisoon, S.R.; Carpenter, R.L.; Rimkus, T.; Anderson, A.; Harrison, A.; Lange, A.M.; Jin, G.; Watabe, K.; Lo, H.-W. Interaction between STAT3 and GLI1/tGLI1 oncogenic transcription factors promotes the aggressiveness of triple-negative breast cancers and HER2-enriched breast cancer. Oncogene 2018, 37, 2502-2514. [CrossRef] [PubMed]

47. Knüpfer, H.; Preiss, R. Significance of interleukin-6 (IL-6) in breast cancer (review). Breast Cancer Res. Treat. 2006, 102, 129-135. [CrossRef] [PubMed]

48. Huang, W.; Dong, Z.; Chen, Y.; Wang, F.; Wang, C.J.; Peng, H.; He, Y.; Hangoc, G.; Pollok, K.; Sandusky, G.; et al. Small-molecule inhibitors targeting the DNA-binding domain of STAT3 suppress tumor growth, metastasis and STAT3 target gene expression in vivo. Oncogene 2015, 35, 783-792. [CrossRef]

49. Heo, T.-H.; Wahler, J.; Suh, N. Potential therapeutic implications of IL-6/IL-6R/gp130-targeting agents in breast cancer. Oncotarget 2016, 7, 15460-15473. [CrossRef]

50. Weng, Y.-S.; Tseng, H.-Y.; Chen, Y.-A.; Shen, P.-C.; Al Haq, A.T.; Chen, L.-M.; Tung, Y.-C.; Hsu, H.-L. MCT-1/miR-34a/IL-6/IL-6R signaling axis promotes EMT progression, cancer stemness and M2 macrophage polarization in triple-negative breast cancer. Mol. Cancer 2019, 18, 1-15. [CrossRef]

51. Conway, M.E.; McDaniel, J.M.; Graham, J.M.; Guillen, K.P.; Oliver, P.G.; Parker, S.L.; Yue, P.; Turkson, J.; Buchsbaum, D.J.; Welm, B.E.; et al. STAT3 and GR Cooperate to Drive Gene Expression and Growth of Basal-Like Triple-Negative Breast Cancer. Cancer Res. 2020, 80, 4355-4370. [CrossRef] [PubMed]

52. McDaniel, J.M.; Varley, K.E.; Gertz, J.; Savic, D.S.; Roberts, B.S.; Bailey, S.K.; Shevde, L.A.; Ramaker, R.C.; Lasseigne, B.N.; Kirby, M.K.; et al. Genomic regulation of invasion by STAT3 in triple negative breast cancer. Oncotarget 2016, 8, 8226-8238. [CrossRef] [PubMed]

53. Huang, L.; Hu, B.; Ni, J.; Wu, J.; Jiang, W.; Chen, C.; Yang, L.; Zeng, Y.; Wan, R.; Hu, G.; et al. Transcriptional repression of SOCS3 mediated by IL-6/STAT3 signaling via DNMT1 promotes pancreatic cancer growth and metastasis. J. Exp. Clin. Cancer Res. 2016, 35, 1-15. [CrossRef] [PubMed]

54. Centurione, L.; Aiello, F.B. DNA Repair and Cytokines: TGF- $\beta$, IL-6, and Thrombopoietin as Different Biomarkers of Radioresistance. Front. Oncol. 2016, 6, 175. [CrossRef] [PubMed]

55. Deshmukh, S.K.; Srivastava, S.K.; Bhardwaj, A.; Singh, A.P.; Tyagi, N.; Marimuthu, S.; Dyess, D.L.; Zotto, V.D.; Carter, J.E.; Singh, S. Resistin and interleukin-6 exhibit racially-disparate expression in breast cancer patients, display molecular association and promote growth and aggressiveness of tumor cells through STAT3 activation. Oncotarget 2015, 6, 11231-11241. [CrossRef] [PubMed]

56. Hartman, Z.C.; Poage, G.M.; Den Hollander, P.; Tsimelzon, A.; Hill, J.; Panupinthu, N.; Zhang, Y.; Mazumdar, A.; Hilsenbeck S.G.; Mills, G.B.; et al. Growth of Triple-Negative Breast Cancer Cells Relies upon Coordinate Autocrine Expression of the Proinflammatory Cytokines IL-6 and IL-8. Cancer Res. 2013, 73, 3470-3480. [CrossRef]

57. Marsden, C.G.; Dragon, J.A.; Wallace, S.S.; Sweasy, J.B. Base Excision Repair Variants in Cancer. Methods Enzymol. 2017, 591, 119-157. [CrossRef] 